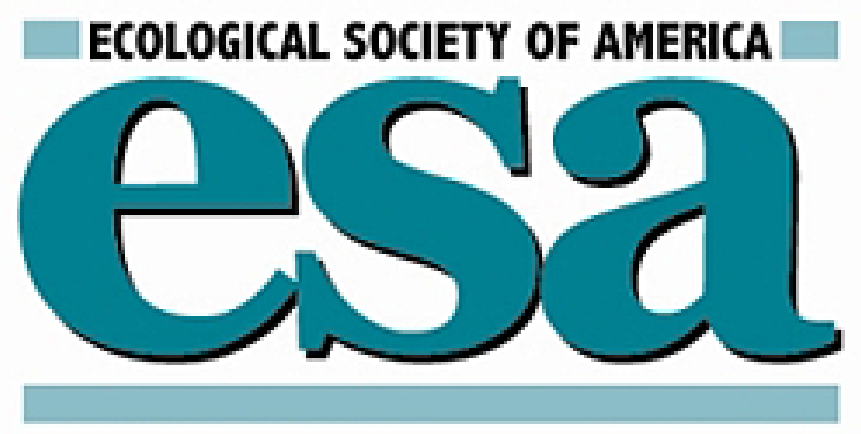

Seed Trait Changes in Dispersers' Guts and Consequences for Germination and Seedling Growth

Author(s): Anna Traveset, Javier Rodríguez-Pérez and Beatriz Pías

Source: Ecology, Vol. 89, No. 1 (Jan., 2008), pp. 95-106

Published by: Ecological Society of America

Stable URL: http://www.jstor.org/stable/27651512

Accessed: 23/02/2015 03:46

Your use of the JSTOR archive indicates your acceptance of the Terms \& Conditions of Use, available at http://www.jstor.org/page/info/about/policies/terms.jsp

JSTOR is a not-for-profit service that helps scholars, researchers, and students discover, use, and build upon a wide range of content in a trusted digital archive. We use information technology and tools to increase productivity and facilitate new forms of scholarship. For more information about JSTOR, please contact support@jstor.org. 


\title{
SEED TRAIT CHANGES IN DISPERSERS' GUTS AND CONSEQUENCES FOR GERMINATION AND SEEDLING GROWTH
}

\author{
Anna Traveset, ${ }^{1,4}$ Javier Rodríguez-Pérez, ${ }^{1}$ and Beatriz Pías ${ }^{2,3}$ \\ ${ }^{1}$ Institut Mediterrani d'Estudis Avançats (CSIC-UIB), C/ Miquel Marqués 21, Esporles, Mallorca E07190 Spain \\ ${ }^{2}$ Departamento de Botánica, Facultade de Farmacia, Universidade de Santiago de Compostela 15782, Santiago de Compostela, Spain \\ ${ }^{3}$ Área de Biodiversidad y Conservación, Universidad Rey Juan Carlos, C/ Tulipán s/n., Móstoles, Madrid E28933 Spain
}

Abstract. The effectiveness of a frugivore as a disperser of a plant is greatly determined by how fruits and seeds are handled in its mouth and its digestive tract. Although a number of studies have investigated the effect of avian ingestion on germination, we still know very little about the modifications to seeds during ingestion and the specific consequences on plant fitness. Here we investigate for the first time the different mechanisms by which germination patterns of seeds are modified following ingestion by frugivores. Specifically, we examine changes in seed mass, water content, permeability, seed coat thickness, texture, and resistance in two common Mediterranean fleshy-fruited plants, Phillyrea angustifolia and Myrtus communis, after ingestion by Eurasian Blackbirds, Turdus merula. We found a number of differences between the plant species: Phillyrea seeds lost mass, mainly due to water loss, and had thinner coats after gut passage, but Myrtus seeds did not. Seeds of both species showed increased permeability, while Myrtus seeds in particular became less resistant to breakage. No quantifiable changes in seed coat texture were detected in either species, although this trait was partly associated with differences in germination rate in Phillyrea. High intraspecific plant variation was found for most seed traits measured.

Seed passage through birds' guts sped up germination in both species, especially in Myrtus. Increased permeability in seeds of both species following ingestion resulted in a higher germination rate. Moreover, seeds with thick coats (and in the case of Phillyrea, harder coats) germinated at a slower rate and produced seedlings that also grew more slowly, indicating a cost of coat thickness and/or hardness for seedling emergence. Results obtained here contribute to explaining the great heterogeneity in germination responses among and within plant species and the large variety of factors, both intrinsic and extrinsic to the plants, that influence such responses.

Key words: avian digestive tract; endozoochory; fruit dispersers; mediterranean fleshy fruits; Myrtus communis; Phillyrea angustifolia; seed germination; seed traits; seedling growth; Turdus merula.

\section{INTRODUCTION}

Fruit and seed treatment in the digestive tract of a frugivorous animal may ultimately determine the capacity of seed germination, and thus may be a crucial component of disperser effectiveness in studies of the population dynamics of endozoochorous plant species (Schupp 1993, Traveset and Verdú 2002, Samuels and Levey 2005, Robertson et al. 2006; Traveset et al. 2007). Such treatment is also important for plant-frugivore interactions from an evolutionary perspective; the specific fruit and seed traits that ultimately determine germination and seedling success in an endozoochorous plant are partly a result of the selection imposed by frugivores (Murray et al. 1994, Cipollini and Levey 1997, Wahaj et al. 1998, Verdú and Traveset 2005).

There are different mechanisms by which frugivores can directly affect seed germination during the process of fruit ingestion. In the first place, frugivores remove

Manuscript received 18 January 2008; revised 18 May 2007; accepted 29 May 2007. Corresponding Editor: T. J. Valone.

4 E-mail: atraveset@uib.es the pulp that surrounds the seed(s); this pulp can decrease and even preclude germination, and so the importance of frugivory as a deinhibition effect can be crucial, at least for some species (Samuels and Levey 2005, Robertson et al. 2006). Secondly, the fecal material embedding the seeds, with a potential fertilizing effect (Dinerstein and Wemmer 1988, Malo and Suárez 1995, Traveset et al. 2001a), as well as the number (Barnea et al. 1992) and combination of seeds in the feces (Loiselle 1990), may influence germination and/or future seedling growth. And, thirdly, the seed coat can be mechanically and/or chemically abraded (scarified) when passing through the digestive tract of a frugivore.

This third mechanism, in particular, is most often invoked when comparing germination patterns between ingested and uningested seeds of the same species (see review in Traveset 1998, Samuels and Levey 2005), although we still have rather little empirical evidence of any alteration of the seed coat structure. The degree of scarification is thought to be dependent upon a variety of factors: (1) the frugivore species that ingests the fruit, with specific morphological traits (e.g., length of 
TABLE 1. Characteristics of fruits and seeds of Phillyrea angustifolia and Myrtus communis.

\begin{tabular}{lccccccc}
\hline \hline & \multicolumn{3}{c}{ Phillyrea } & & \multicolumn{3}{c}{ Myrtus } \\
\cline { 2 - 3 } \multicolumn{1}{c}{ Trait } & Mean $\pm \mathrm{SE}(n=400)$ & $\mathrm{CV}_{\text {seed }}$ & $\mathrm{CV}_{\text {plant }}(n=10)$ & & Mean $\pm \mathrm{SE}(n=250)$ & $\mathrm{CV}_{\text {seed }}$ & $\mathrm{CV}_{\text {plant }}(n=10)$ \\
\hline Fruit length (mm) & $6.03 \pm 0.04$ & 0.172 & 0.124 & & $8.31 \pm 0.38$ & 0.149 & 0.122 \\
Fruit mass (mg) & $195.5 \pm 15.9$ & 0.183 & 0.256 & & $304.1 \pm 18.9$ & 0.147 & 0.164 \\
No. seeds/fruit & 1.0 & & & & $9.8 \pm 1.4$ & 0.195 & 0.371 \\
Seed length (mm) & $5.09 \pm 0.20$ & 0.164 & 0.127 & & $3.19 \pm 0.10$ & 0.134 & 0.086 \\
Seed mass (mg) & $36.8 \pm 3.07$ & 0.301 & 0.263 & & $8.21 \pm 0.56$ & 0.063 & 0.179 \\
\hline
\end{tabular}

Note: Both the coefficient of variation within a plant $\left(\mathrm{CV}_{\text {seed }}\right)$ and among plants $\left(\mathrm{CV}_{\text {plant }}\right.$, obtained from the mean of each plant $)$ are shown for each species.

digestive tract, presence of a gizzard), physiological traits (e.g., digestive fluids in the gut, with variable water content, $\mathrm{pH}$, proportion of plant material), and gut passage times (Murray et al. 1994, Traveset et al. 2001b, Santamaría et al. 2002, Charalambidou et al. 2005, Pollux et al. 2005, Tewksbury et al. 2008); (2) the type of food ingested along with seeds (Barnea et al. 1990, Traveset 1998); and (3) intrinsic fruit and seed traits (e.g., pulp composition, seed age, seed size, coat thickness, texture). Some of these traits may affect seed retention time in the digestive tract and thus determine the extent to which seed coat is modified; for instance, seeds embedded in pulp with laxative compounds remain for short periods within birds' guts (Murray et al. 1994, Wahaj et al. 1998), whereas the opposite occurs when pulp contains constipating substances (Cipollini and Levey 1997, Tewksbury et al. 2008). Also, small seeds are usually retained longer in frugivores' guts than are large seeds (Levey and Grajal 1991, Stanley and Lill 2002). The extent to which seed germination patterns are altered is likely to be a function of the level of seed scarification (Marrero and Nogales 2005, Nogales et al. 2005, Rodríguez-Pérez et al. 2005, Tewksbury et al. 2008); however, we need more data concerning this subject.

The main goal of the present work was thus to identify mechanisms that can explain the germination responses of seeds ingested by frugivores when compared to seeds that have not passed through any digestive tract. For the first time, we empirically tested whether ingested seeds experience various types of modifications in their coats and whether such changes can explain the germination patterns observed. We further take into account the intraspecific variability in plant germination responses, rarely considered in these germination studies (Meyer and Witmer 1998), as well as the effect of individual frugivores, as this is known to influence germination responses (Santamaría et al. 2002, Charalambidou et al. 2003, 2005). We carried out the study with two common fleshy-fruited Mediterranean species, Phillyrea angustifolia L. (Oleaceae) and Myrtus communis L. (Myrtaceae) (see Plate 1), mainly dispersed by birds, and tested the germination behavior of seeds passed through the Eurasian Blackbird, Turdus merula (Turdidae), a widespread frugivorous passerine species in the Mediterranean region (Barnea et al. 1991). Our specific questions were as follows: (1) Do seeds become more permeable and change their mass when passing through the birds' digestive tracts? (2) Is there seed abrasion within the birds that results in thinner seed coats and/or coats that are easier for the emerging seedlings to break open (because of an increased porosity, for instance)? (3) Is the seed coat ultrastructure modified in a quantifiable way? (4) Is there any association between changes in those variables (responses to ingestion) and patterns of germination and seedling growth? (5) What is the degree of intraspecific variation in such responses to ingestion?

\section{Material and Methods}

\section{Study species}

Phillyrea angustifolia (hereafter Phillyrea) is an androdioecious evergreen small tree, up to $7 \mathrm{~m}$ tall, with a masting reproduction (Traveset 1994). Its blue drupes are available from late August throughout the autumn. Fruit and seed traits vary notably among individual plants (Table 1). Myrtus communis (hereafter Myrtus) is a hermaphrodite evergreen shrub that can reach up to $5 \mathrm{~m}$ in height. There are two color morphs of the berries (blue and white/yellowish), but they show no significant differences in seed removal, seed germination patterns, or seedling growth (Traveset et al. 2001b). Berries of either morph contain an average of 9.8 seeds and are available from November to February. Both fruit and seed traits also vary considerably among individual plants (Table 1). The main dispersers of both species are birds, although carnivorous mammals such as foxes, martens, and weasels, as well as reptiles (lizards in the case of Phillyrea), consume the fruits in nature and disperse the seeds intact (Aronne and Russo 1997, Traveset et al. 2001b). Fruits of both species were collected from Port des Canonge, an area located at sea level in northwestern Mallorca (Balearic Islands, Spain, Western Mediterranean).

Eurasian Blackbirds (Turdus merula; Turdidae) are one of the main dispersers of fleshy-fruited plants in the Balearic Islands. They are relatively abundant in these islands and are present throughout the year. During September and October 2002, we captured four individuals by means of mist nets in an orchard, and housed them separately in metal cages $(60 \times 60 \times 60 \mathrm{~cm})$ in an indoor aviary until the end of the experiment, when they 
were released at their site of origin. Birds were maintained on a mixed diet of commercial food (dry fruits and insects; Ditta All Pet, Caronno, Pertusella, Varese, Italy) for insectivores and wild fleshy fruits (the same used for experimental trials). Food was available ad libitum during such maintenance period. Birds were left to acclimate for 2-3 days before the start of the experiment. A screen that prevented birds from seeing each other was placed between cages to reduce stress Birds had continuous access to a water source in the cages.

\section{Modification of seed traits}

We collected fruits from 10 (Phillyrea) and seven (Myrtus) individual plants during the fall of 2002. In the case of Myrtus, only blue fruits were gathered in order to minimize any possible effect of fruit morph (even though no effects were detected in a previous study; Traveset et al. 2001b). Fresh fruits from the different individuals were collected on different days (a maximum of two individuals per day), during 1-18 October for Phillyrea and during 22-31 October for Myrtus. They were kept in the refrigerator until being used. The test with captive birds was performed within the first 48 hours after fruit collection in all cases. We first tested the 10 individuals of Phillyrea with each of the four blackbirds, continuing with Myrtus afterward. When we began the test with the third individual of Myrtus, one of the blackbirds showed signs of ill health and therefore was removed from the experiment. For this species, thus, we obtained data from four blackbirds for the first two plants and from three blackbirds for the remaining five plants.

Between 40 and 60 randomly chosen fruits from an individual plant were given to each blackbird in the morning, between 09:00 and 10:00 hours; this was repeated during 10 days, each day with a different individual plant. This avoided any mixing of seeds from different individual plants in the birds' digestive tracts. When the four birds had voluntarily consumed all fruits (force-feeding was never necessary; the few fruits that were dropped by birds in the cages were latter discarded), we collected all defecated seeds and stored them separately, for each individual plant and bird. This was usually done between 12:00 and 15:00 hours. After this time, birds were fed with commercial food, and in the evening (around 19:00 hours), cages were cleaned for the next experiment the following morning. Gut passage time in Eurasian Blackbirds is usually about 30 minutes, although some seeds can be retained longer (Barnea et al. 1991; M. Sobral, unpublished data). We discarded any seeds that might have been defecated after 15:00 hours, although we are confident that this was negligible and that most, if not all, seeds consumed by each bird were defecated in the first 5-6 hours after consumption.

From the same pool of fruits from each individual plant, we randomly picked 120 fruits of Phillyrea and 100 fruits of Myrtus and manually depulped them. These uningested seeds were used as controls, and did not differ in size from those used for the ingestion treatment $\left(F_{1,9}=0.18\right.$ and $F_{1,6}=0.01$ for Phillyrea and Myrtus, respectively, $P>0.30$ ). The depulping of seeds of a given individual plant was done during the same morning when the fruits of that individual were given to birds; thus, the fruits from which these control seeds were obtained remained for exactly the same time in the refrigerator as the fruits fed to birds.

Seeds were gathered from either the fecal material or from the pulp by means of forceps, without rinsing them. Both type of seeds (defecated and depulped) were placed within petri dishes and were left at room temperature during the same period of time. For the coat permeability and germination tests, we used seeds immediately (the same day or the following day) after depulping and retrieval from feces, storing the rest of the seeds in glass vials at room temperature for the other tests. In the case of Myrtus berries, we considered only the individual plant variation and not the intra-fruit variation; we thus chose random seed samples from each individual plant for each test. The specific tests were carried out to quantify the following variables.

1. Water content.-From each individual plant, 40 ingested seeds (10 retrieved from each blackbird) and 40 depulped seeds (30-40 in the case of Myrtus) were measured (maximum length, $\pm 0.1 \mathrm{~mm}$ ) and weighed $( \pm 0.1 \mathrm{mg})$ while still fresh. These seeds were dried at $70^{\circ} \mathrm{C}$ for 24 hours, and were then reweighed. Seed water content (hereafter SWC) was estimated as the difference between fresh and dry mass relative to fresh seed mass. We used a total of 800 Phyllirea seeds and 480 Myrtus seeds for this test.

If seeds had been hydrated in the frugivores' guts, we would expect a higher SWC and, all other things being equal, a greater mass of ingested seeds compared to controls. However, seed mass might differ between treatments due to a possible abrasion of the coat in ingested seeds, without necessarily having been hydrated.

2. Seed coat permeability (or capacity of water absorption).-The permeability to water of ingested seeds might be modified without causing a detectable change in SWC if, for instance, seeds remain in the bird's gut too short a time to gain or lose water. For this reason, we quantified the capacity of water absorption in ingested and control seeds as a measure of permeability. Such capacity might actually be very important for the germination of the two study species because they are dispersed and germinate during the fall-winter period, when humidity is high and rains are more likely in the Mediterranean region. Although here we dealt only with permeability to water, oxygen is the other substance commonly absorbed by seeds and is essential for germination (Rick and Bowman 1961, Baskin and Baskin 1998). We chose another group of 40 ingested seeds (also 10 retrieved from each blackbird) and 40 depulped seeds from each individual plant, and measured and weighed them while fresh. These seeds were 
immediately submerged in $200 \mathrm{~mL}$ of distilled water for 24 hours, and were then reweighed. Seed coat permeability (hereafter SCP) was quantified as the difference between hydrated and fresh mass relative to seed dry mass (dry rather than fresh mass was used as denominator because, at least in the case of Phillyrea, ingested seeds lost water, which might have affected their capacity to absorb water; see Results). These hydrated seeds were later used for the germination experiment, so we obtained their dry mass by extrapolating from the relationship between fresh and dry mass for each individual plant and treatment in a model-II regression from the water content test. For each species, seed coat permeability was tested with the same number of seeds used to determine seed water content.

3. Seed coat thickness.-Random samples of five control seeds from each plant and five ingested seeds per plant from each bird were used to measure the thickness of the seed coat. We dissected each seed in two halves and placed one half under a binocular scope (at $125 \times$ in the case of Phillyrea and $200 \times$ in the case of Myrtus). Five measurements of coat thickness were recorded for each seed (a total of 1250 measurements from 250 Phillyrea seeds and 675 measurements from 135 Myrtus seeds); seed length was also recorded to control for seed size in the statistical analysis. The software used was Image Pro-Plus Version 4.5.1.2.2 (MediaCybernetics 2001).

4. Seed hardness (or resistance to breakage).-From each species and for each individual plant, we obtained another sample of control seeds (10 per plant) and ingested seeds ( 3 per blackbird per plant for Phillyrea and 10 per blackbird per plant for Myrtus), recording the diameter of each seed before testing the load needed to break the coat. We quantified this variable by means of a testing machine (compression mode; Zwick/Z100, Ulm, Germany). Seeds were placed in a metal platform (diameter $13.5 \mathrm{~cm}$ ) and compressed along their longitudinal axes. The crosshead moved down at a fixed speed $(5 \mathrm{~mm} / \mathrm{min}$ for Phillyrea and $2 \mathrm{~mm} / \mathrm{min}$ for the smaller seeds of Myrtus) and the seed was deformed until the coat broke open. The machine was connected to computer software (testXpert Version 4.01; Zwick, Ulm, Germany), giving three variables of interest here: (1) load (in newtons) applied on the seed at breakage time; (2) deformation (in $\mathrm{mm}$ ), that is, the distance run by the crosshead from where it touches the seed until it breaks it; and (3) work (in Nmm), which is the integral of load across such deformation, and is presumably correlated with the work a seedling should do to emerge (but see Discussion). Some seed measurements were lost while being tested; we ended up with a total of 220 and 260 Phyllirea and Myrtus seeds, respectively, for this test.

5. Seed coat structure.-From each of six individuals of each plant species, we took a random sample of five control seeds and five ingested seeds (for logistic reasons, in this case we did not consider individual variation among frugivores) and analyzed them with the Scanning Electronic Microscope (SEM) Hitachi S530 (Hitachi, Tokyo, Japan) with a voltage of $15 \mathrm{kV}$. Seeds were previously covered with gold inside a Polaron E5100 sputter coater (Polaron, Cambridge, UK). All seeds were exposed to the gold coverage during the same period of time. A digital image $(100 \times)$ was obtained from each seed, for a total of 120 images. From each image, we then computed several indices characterizing the texture of the seed coat as quantitative measures of the coat structure (J. Martín and A. Traveset, unpublished manuscript). Among several indices, the element difference moment of order two of the gray-level coocurrence matrix, a second-order statistic describing the probability of adjacency of two different gray levels (hereafter MM index; Haralick et al. 1973, González and Woods 2002) yielded the best results, that is, the highest correlations with germination responses. We therefore obtained the MM index for 10 different areas in each photograph, avoiding any artefact (such as strange particles and areas of the image that were under or overexposed) that might considerably alter the measurements. Such an index is independent of the size of the measured area, once a minimum surface area (representative of the textural features of interest) has been established.

\section{Seed germination behavior and seedling growth}

Seeds used to test coat permeability were sown in an experimental garden in order to determine possible differences among treatments and individuals and to assess whether any of the variables measured were correlated with seed germination responses and seedling growth. Seeds were individually and randomly planted in trays of 60 pots $(4 \times 4 \mathrm{~cm})$. Each pot was filled with horticultural mixture in which the seeds were planted at a depth of $\sim 0.5 \mathrm{~cm}$. Both control and ingested seeds from each individual plant were planted simultaneously, usually the first day after the test had been done with the birds. In the meantime, control and defecated seeds were always kept under the same conditions: dry and at room temperature. Phillyrea seeds were planted between 1 and 18 October 2002, whereas Myrtus seeds were planted between 22 October and 7 November 2002. Trays were watered twice a week to ensure permanent humidity, and seed germination was monitored every $3-5$ days. We considered germination rate, defined as the speed at which seeds germinate (the cotyledons emerge) and calculated as the number of days a seed takes to germinate, as the main seed response to ingestion. At the end of the experiment (15 July 2003), we measured the maximum height $( \pm 1 \mathrm{~mm})$ and number of leaves of each emerged seedling.

\section{Statistical analyses}

For all measured seed traits, the effects of treatment, plant, and bird were tested by means of general linear models (GLM). In all models, we included treatment as 


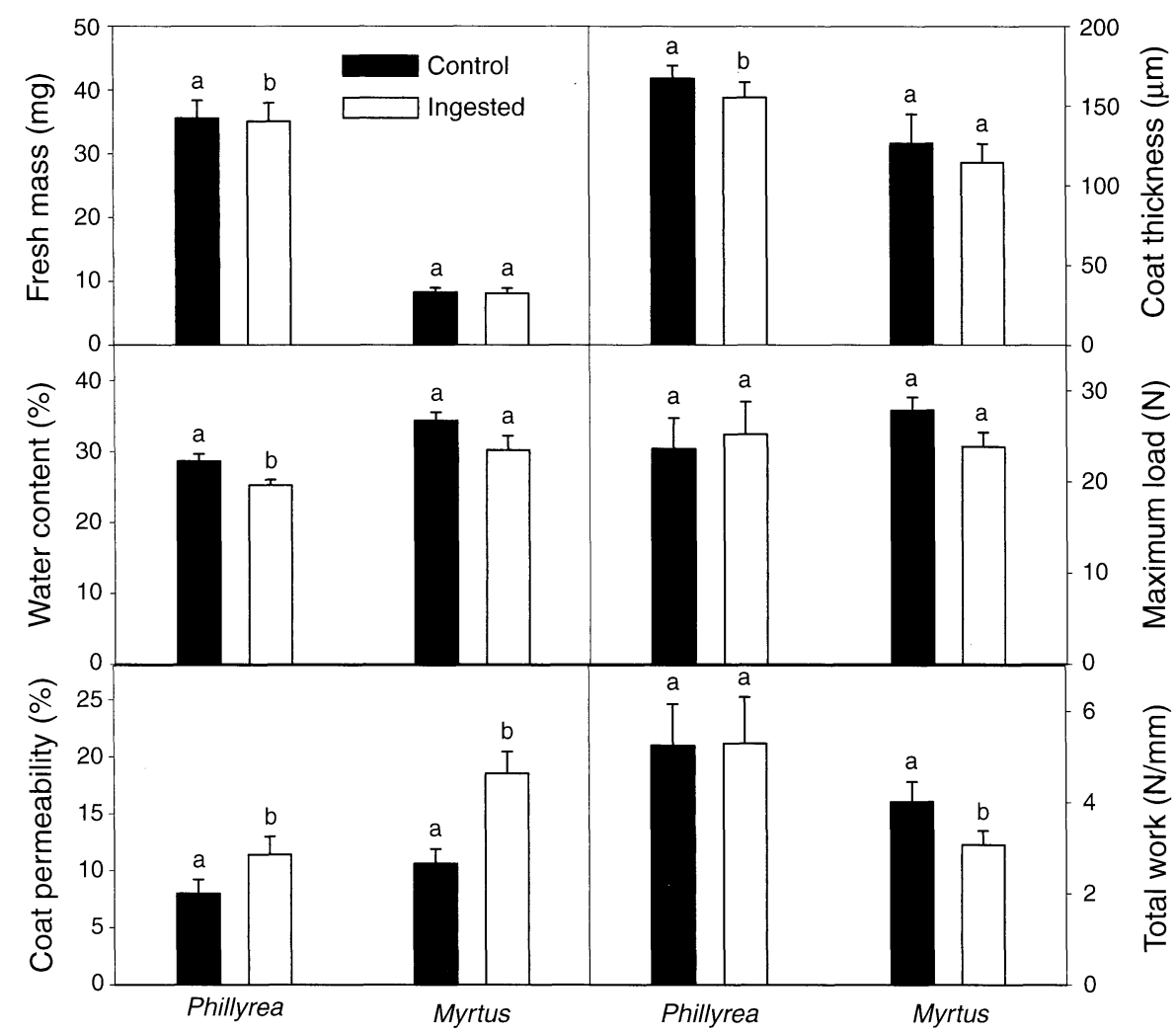

FIG. 1. Different traits (mean + SE) of Phillyrea angustifolia and Myrtus communis seeds either ingested by Eurasian Blackbirds (Turdus merula) or collected directly from plants (hand-cleaned seeds; control group). Within each species, columns with different lowercase letters are significantly different $(P<0.05)$. For maximum load and total work, $\mathrm{N}$ represents newtons.

a fixed factor and plant and bird as random factors. When testing for differences among individual birds, we considered only ingested seeds. The angular transformation was used to normalize SWC and SCP, whereas seed coat texture and thickness and seed hardness were transformed logarithmically. Seed length was included as a covariate in all tests (except for texture) after testing for homogeneity of slopes.

In the analysis of seedling growth (height and number of leaves per seedling), we incorporated two covariates in the model: (1) seed length and (2) number of days elapsed between sowing and emergence for each seed. The blackbird effect was also tested in separate analyses for each species. Both seedling height and number of leaves were logarithmically transformed before analyses. All GLMs were performed using the STATISTICA 6.0 package for Windows (StatSoft 2005).

The effect of seed ingestion on germination rate for each species was tested using failure-time analysis. A Cox proportional-hazard regression model was fitted to the number of days between sowing and emergence for each seed, including treatment (fixed) and plant (random) as categorical predictors and seed length and coat permeability as continuous covariates. Non-germinated seeds were modeled as right-censored data points, due to the uncertainty that they could eventually germinate after the study period. The analyses were executed using the program S-Plus 2000 (MathSoft 1999). The effect of different treatments was compared to controls.

Finally, we performed a regression analysis (General Regression Model in STATISTICA) for each species to investigate the effect of seed water content, seed coat thickness, seed hardness, and seed coat texture on germination rate and seedling growth; treatment (ingestion) was a categorical predictor in both models. In Phillyrea, seed coat thickness was highly associated with seed hardness; thus, only the former was introduced as a continuous predictor in the model, because this variable differed significantly between ingested and control seeds (see Results). Seed coat texture was considered only for Phillyrea because this variable notably decreased the adjusted $r^{2}$ of the models for Myrtus, besides not being significant. Likewise, seed water content was not included in the models because it had no significant effect on germination or seedling growth patterns and decreased the adjusted $r^{2}$ in both cases.

\section{RESUlts}

Effect of ingestion on seed mass and water content

Ingested Phillyrea seeds appeared to be slightly lighter than non-ingested controls (Fig. $1 ; F_{1,9}=7.50, P=0.02$ ). Although seed mass differed significantly among indi- 

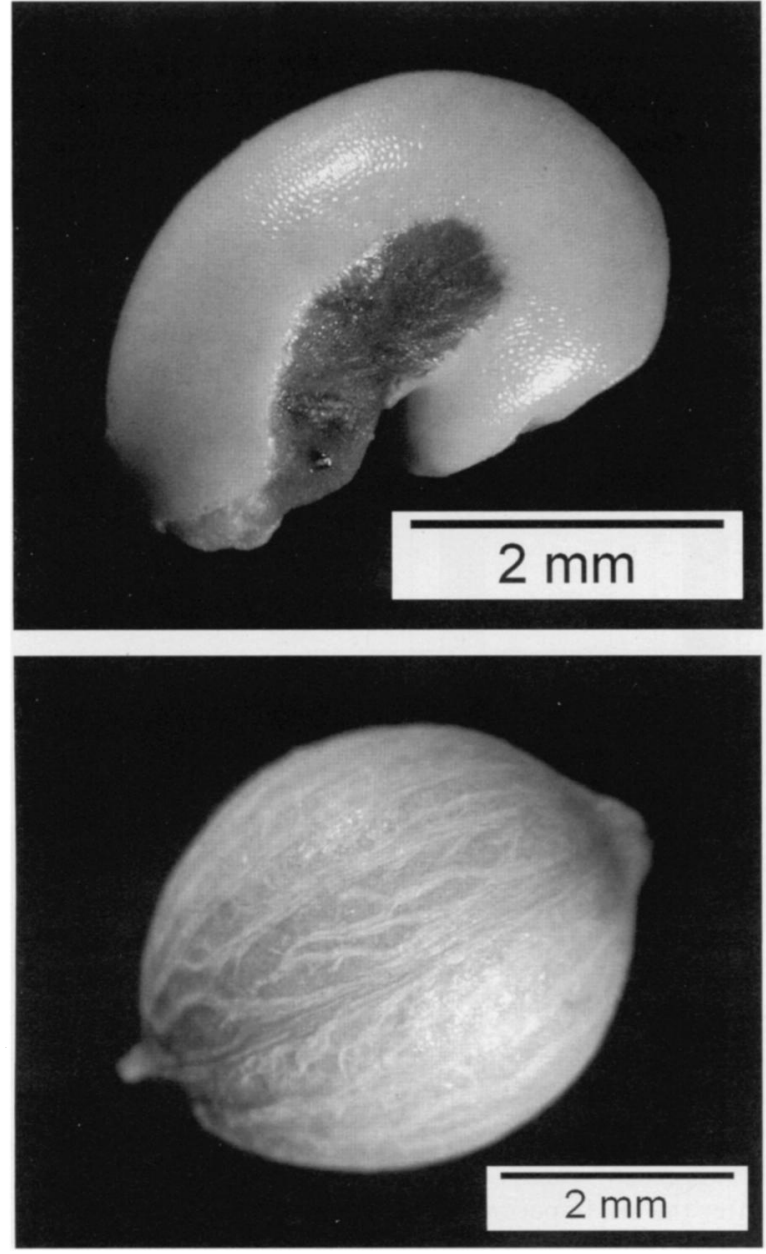

Plate 1. Seeds of Myrtus communis (above) and Phillyrea angustifolia (below) used to test for changes in seed traits after being ingested by frugivorous birds. Photo credits: A. Traveset.

vidual plants $\left(F_{9,9}=34.03, P<0.0001\right)$, the decline in seed fresh mass after ingestion was fairly consistent (interaction treatment $\times$ plant: $F_{9,779}=1.65, P=0.10$ ). Moreover, SWC was also greater in controls than in ingested seeds (Fig. $1 ; F_{1,9}=11.86, P<0.01$ ), indicating that seeds lose water (an average of $\sim 5 \%$ ) when traveling through the birds' digestive tracts. There appeared to be no differences among individual plants in SWC $\left(F_{9,9}=2.35, P=0.11\right)$, but they responded differently to ingestion, some losing much more water than others $\left(F_{9,779}=10.23, P<0.0001\right)$. Seed length had a significant effect on fresh seed mass $\left(F_{1,779}=431.09, P\right.$ $<0.0001)$ although not on water content $\left(F_{1,779}=0.14\right.$, $P=0.71$ ); that is, large seeds are heavier, but do not necessarily contain more water than small seeds. SWC was also found to be independent, at the individual plant level, of other intrinsic traits such as seed coat thickness $\left(r_{\mathrm{s}}=0.14, P=0.70, n=10\right.$; only control seeds considered). Likewise, the proportion of water lost during passage through birds was not associated with either seed length or coat thickness $\left(r_{\mathrm{s}}=0.48, P=0.16\right.$, and $r_{\mathrm{s}}=0.10, P=0.78$, respectively, $n=10$ individuals).

A greater variation among plants was found in the case of Myrtus. Although no significant changes in seed mass were observed after ingestion (Fig. 1; $F_{1,6}=0.11, P$ $=0.75$ ), there were differences among individuals; seeds of most but not all plants lost mass when passing through birds' digestive tracts (interaction: $F_{6,465}=7.04$, $P<0.001)$. Similarly, the ingestion effect on SWC was not significant $\left(F_{1,6}=2.06, P=0.20\right)$ and varied significantly among individuals (interaction: $F_{6,459}=$ 14.30, $P<0.001$ ). Large Myrtus seeds were heavier $\left(F_{1,465}=123.92, P<0.001\right)$ and contained more water than small seeds $\left(F_{1,459}=6.66, P=0.04\right)$. Likewise, individuals with high values of SWC had thinner seed coats $\left(r_{\mathrm{s}}=-0.86, P=0.01, n=7\right.$; only controls were considered), regardless of seed size. Moreover, individuals with large and thick-coated seeds marginally tended to lose a lower proportion of water than those with small and thin-coated seeds $\left(r_{\mathrm{s}}=-0.71, P=0.07\right.$, and $r_{\mathrm{s}}=$ $-0.68, P=0.09$, respectively; $n=7$ ).

For either species, no overall effect of blackbird on either seed mass or SWC was detected (results not shown).

\section{Effect of seed passage on water absorption capacity}

Ingested seeds of both Phillyrea and Myrtus showed a greater SCP than control seeds, although the ingestion effect was much more important for Myrtus (Fig. 1; $F_{1,9}$ $=4.42, P=0.06$ and $F_{1,6}=28.51, P=0.002$, respectively). There was much variation in SCP among plants of both species $\left(F_{1,9}=7.99, P=0.002\right.$ and $F_{1,6}=$ $4.23, P=0.05$, respectively), and the effect of ingestion depended upon the individual plant (interaction: $F_{9,779}=$ $11.61, P<0.0001$ and $F_{6,465}=2.41, P=0.03$, respectively). Seed length was not associated with SCP in Phillyrea $\left(F_{1,779}=1.23, P=0.27\right)$; by contrast, large Myrtus seeds were more permeable than small ones $\left(F_{1,465}=5.53, P=0.02\right)$.

As in the case of seed mass or SWC, the effect of individual blackbird on SCP was negligible. The association between proportion of water loss (SWC control - SWC ingested/SWC control) during seed ingestion and SCP was tested on an individual plant basis, because these two variables were obtained with different seeds from each individual. We found no significant correlation in any of the two species $\left(r_{\mathrm{s}}=\right.$ $0.53, P=0.12, n=10 ; r=0.14, P=0.76, n=7$ for Phillyrea and Myrtus, respectively), suggesting that individuals whose seeds lose more water during passage through a bird are not necessarily those with greater capacity of water absorption.

\section{Effect of seed passage on coat structure and thickness and seed hardness}

We detected no significant change in coat texture (MM index) of seeds passed through blackbirds' digestive tracts, either in Phillyrea $\left(F_{1,5}=0.09, P=\right.$ 
$0.78)$ or in Myrtus $\left(F_{1,5}=0.94, P=0.38\right)$. Plant source was not a relevant predictor of coat texture $(P>0.05$ for both species), although the effect of treatment on such texture varied among individual plants in both species $\left(F_{5,48}=10.67, P<0.001\right.$ and $F_{5,48}=3.15, P<0.02$, respectively).

Changes in seed coat thickness were observed after ingestion only in Phillyrea. Ingested seeds had a thinner coat than controls (Fig. $1 ; F_{1,9}=12.67, P<0.01$ ). There was much variation among individuals $\left(F_{9,9}=19.90, P\right.$ $<0.001)$, and the effect of treatment on such a variable also differed among individuals $\left(F_{9,229}=2.25, P=0.02\right)$. No changes were detected in Myrtus seeds $\left(F_{1,6}=0.34, P\right.$ $=0.57)$ and there was not much variation among individuals in that variable $\left(F_{6,6}=1.23, P=0.41\right)$, although the effect of ingestion varied slightly among them (Fig. 2; $F_{6,107}=2.29, P=0.04$ ). The effect of blackbird on this variable for either plant species was again irrelevant (results not shown). Seed length had no significant influence on coat thickness in any of these analyses (all $P>0.05$ ).

The measurements of seed hardness also differed between the two species. The maximum load needed to break Phillyrea seeds did not differ between control and ingested seeds (Fig. 1; $F_{1,9}=0.93, P=0.36$ ); likewise, control and ingested seeds showed a similar deformation before breaking $\left(F_{1,9}=1.17, P=0.31\right)$ and needed a similar total work to break open (Fig. $1 ; F_{1,9}=3.83, P=$ 0.11). Plants differed among control and ingested seeds in all three variables (all $P<0.05$ ), but there was no significant plant $\times$ treatment interaction for any of them (all $P>0.05$ ). In a separate correlation analysis, individuals with thick seed coats also had harder (more resistant) seeds $\left(r_{\mathrm{s}}=0.74, P=0.006, n=20\right)$. In Myrtus, the maximum load needed to break the seeds did not differ between treatments (Fig. 1; $F_{1,6}=2.98, P=0.13$ ), although deformation was marginally higher in control than in ingested seeds $\left(F_{1,6}=4.13, P=0.08\right)$ and total work needed to break the seeds was significantly lower for ingested than for control seeds $\left(F_{1,6}=5.63, P=0.02\right)$. No effect of individual Myrtus plants and no treatment $X$ plant interaction were found for any of the three variables (all $P>0.05$ ). Moreover, seed length showed a consistent nonsignificant effect on them.

Only a slight blackbird effect on both load and work need to break seeds was observed in Phillyrea, whereas no such effect was found in Myrtus (results not shown).

\section{Seed germination rate and seedling growth}

The rate at which seeds germinated was only slightly higher for ingested than for control seeds in Phillyrea $\left(\chi^{2}\right.$ $=5.30, P<0.02)$, but was significantly higher in the case of Myrtus (Fig. 2; $\chi^{2}=24.51, P<0.0001$ ). For both species, there were significant differences among individual plants $\left(\chi^{2}=121.17, P<0.001\right.$ and $\chi^{2}=61.21, P$ $<0.001$, respectively). Of the two covariates included in the models (seed length and coat permeability), only the latter showed a significant and positive effect on
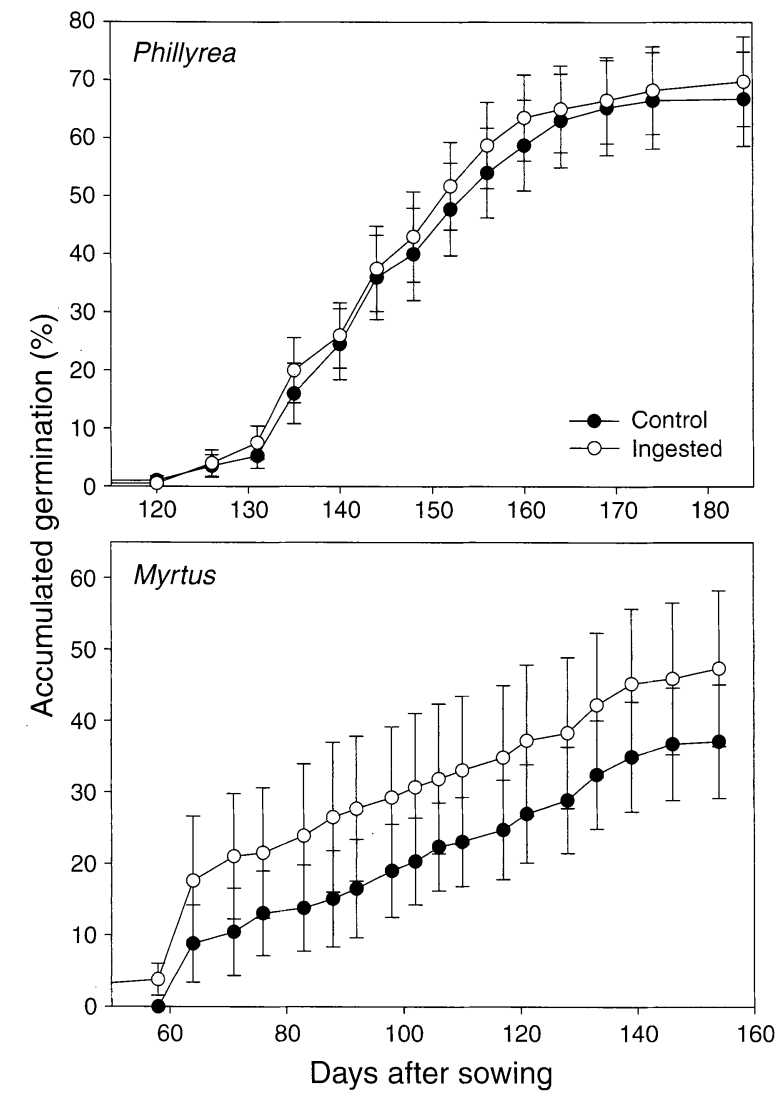

FIG. 2. Patterns in cumulative percentage of seeds germinating (mean $\pm \mathrm{SE}$ ) for $P$. angustifolia and $M$. communis seeds either ingested by Eurasian Blackbirds (T. merula) or collected directly from plants (hand-cleaned seeds; control group).

germination rate $\left(\chi^{2}=18.83, P<0.0001\right.$ and $\chi^{2}=$ 20.56, $P<0.0001$ for Phillyrea and Myrtus, respectively). No effect of blackbird on germination rate was detected for either plant species (all $P>0.05$ ).

Neither of the two variables describing seedling size (height or number of leaves per seedling) differed between ingested and control seeds, after controlling for the time elapsed since germination and for seed size (length), for either Phillyrea or Myrtus (all $P>0.05$ ), suggesting that seedling vigor is independent of whether seeds passed through a digestive tract or not. Differences in seedling height existed among individual plants $\left(F_{9,500}=9.39, P=0.0005\right.$ and $F_{4,139}=41.06, P=$ 0.0001 for Phillyrea and Myrtus, respectively) but there was no interaction between plant and treatment.

In the regression analysis, the effect of treatment on Phillyrea germination rate was not significant, but both seed texture and coat thickness were found to be significantly associated with it (Table 2); seeds with high values of the MM texture index and seeds with thick coats took longer to germinate than those with low MM values or with thin coats. When seed hardness was included in the model instead of coat thickness (both 
TABLE 2. Results of multiple regressions performed to explain variability in germination performance, seedling height, and seedling growth rate in Phillyrea angustifolia and Myrtus communis.

\begin{tabular}{|c|c|c|c|c|c|c|c|}
\hline \multirow[b]{3}{*}{ Dependent variable } & \multirow[b]{3}{*}{ Adj. $r^{2}$} & \multirow[b]{3}{*}{ df } & \multirow[b]{3}{*}{$F$} & \multicolumn{4}{|c|}{ Independent variables } \\
\hline & & & & \multicolumn{2}{|c|}{ Seed coat texture } & \multicolumn{2}{|c|}{ Seed coat thickness } \\
\hline & & & & $\beta$ & $t$ & $\beta$ & $t$ \\
\hline \multicolumn{8}{|l|}{ Phillyrea } \\
\hline Germination rate & 0.77 & 3,8 & $13.27 * * *$ & $0.48 \pm 0.16$ & $2.87^{*}$ & $0.58 \pm 0.17$ & $3.39 * *$ \\
\hline Seedling height & 0.32 & 3,7 & 2.54 & $0.73 \pm 0.31$ & $2.36 \dagger$ & $-0.86 \pm 0.36$ & $-2.40^{*}$ \\
\hline Seedling growth rate & 0.38 & 3,7 & 3.05 & $0.38 \pm 0.29$ & 1.31 & $-0.99 \pm 0.34$ & $-2.87 *$ \\
\hline \multicolumn{8}{|l|}{ Myrtus } \\
\hline Germination rate & 0.38 & 3,10 & $3.62 \dagger$ & & & $0.51 \pm 0.23$ & $2.25^{*}$ \\
\hline Seedling height & 0.37 & 3,10 & $3.51 \dagger$ & & & $-0.71 \pm 0.23$ & $-3.11 * *$ \\
\hline Seedling growth rate & 0.19 & 3,10 & 2.01 & & & $-0.47 \pm 0.26$ & -1.84 \\
\hline
\end{tabular}

Notes: Significance levels are designated as follows: $\dagger P=0.05 ;^{*} P<0.05 ; * * P<0.01 ; * * *<0.001$. For details, see Results: Seed germination rate and seedling growth.

variables being highly correlated in this species), the entire model was still highly significant (adjusted $r^{2}=$ $0.65 ; F=7.76, P<0.01$ ) although the effect was only marginally significant $(\beta=0.47, t=2.18, P=0.06)$. Despite no overall effect of treatment being detected on either seedling height or growth rate, seedlings coming from seeds with thicker coats tended to be shorter and to grow at a slower rate. Seed texture showed only a marginal effect on seedling height and no effect on growth rate (Table 2). In the Myrtus regression models, the effect of treatment was again nonsignificant, but seed coat thickness was associated with both germination rate and seedling height, as in Phillyrea, but was not associated with seedling growth rate (Table 2). Seed hardness was not associated with any of those three variables, in contrast to results for Phillyrea.

\section{Discussion}

\section{Changes in seed traits}

Given the scarce information available on the modifications that seeds experience after being ingested by frugivores, we believe that a few generalizations can be made on the mechanisms underlying the differences typically observed in germination patterns between ingested and uningested seeds. In this study, we found that such mechanisms appear to be species specific, because the effect of ingestion on most variables examined differed between Phillyrea and Myrtus. Moreover, a seed trait that influences germination patterns in one species may not have the same effect in another species.

Seed mass in Phillyrea decreased after ingestion by blackbirds, whereas Myrtus seeds showed no mass changes. A decline in seed mass has been reported in a number of species (Traveset et al. 2001c, RodríguezPérez et al. 2005), although not in others (Paulsen and Högstedt 2002, Rodríguez-Pérez et al. 2005). The mass loss in Phillyrea seeds is partly due to loss in water content $(\sim 5 \%)$, which might result from an osmotic process when soluble concentration is high within the bird's gut. Differences among individual plants in the effect of seed ingestion on water loss might reflect differences in seed coat permeability. However, at the individual level, no association was observed between the proportion of seed water loss and the capacity of water absorption; moreover, such water loss was not associated with intrinsic seed traits such as size or coat thickness. The amount of water a seed loses while traveling through a frugivore's gut may be more likely to depend mostly upon the "context" in which it is found (i.e., the food material within the digestive tract), as well as upon endogenous factors (e.g., the concentrations of reserve substances) within the seed. In Myrtus, the changes in either seed mass or water content after ingestion also varied among individuals, depending upon intrinsic seed traits such as size and coat thickness; plants with large seeds or with thick-coated seeds retained a greater proportion of water when being ingested by birds than did plants with small or thincoated seeds. There was a trend for large Myrtus seeds to be more permeable than small seeds, but, as mentioned before, water loss might be related to the concentration of substances (e.g., amino acids, proteins, lipids.) within the seeds, regardless of their size. Seed water content has been reported to decrease during seed development in some species (Egli 1994). In our case, fruits were collected when completely ripe and we discard the possibility that a fraction of the seeds were still immature when given to birds. As in Phillyrea, ingested Myrtus seeds increased their permeability, but the changes in this variable were not associated with changes in seed water content.

Seeds of the same individual plant may respond differently to ingestion depending on the bird that consumes them, as shown by the significant interactions observed in both species between plant and blackbird effects on seed water content and permeability. We know from other studies that different species of frugivores can have different effects on the germination response of a particular plant (reviewed in Traveset 1998), and there is also evidence that the diet of a particular frugivore can influence germination (Levey 
TABle 2. Extended.

\begin{tabular}{|c|c|c|c|}
\hline \multicolumn{4}{|c|}{ Independent variables } \\
\hline \multicolumn{2}{|c|}{ Work } & \multicolumn{2}{|c|}{ Treatment } \\
\hline$\beta$ & $t$ & $\beta$ & $t$ \\
\hline & & $\begin{array}{r}-0.14 \pm 0.15 \\
0.25 \pm 0.31 \\
0.23 \pm 0.30\end{array}$ & $\begin{array}{r}-0.92 \\
0.80 \\
0.77\end{array}$ \\
\hline $\begin{array}{r}0.35 \pm 0.25 \\
0.40 \pm 0.25 \\
-0.32 \pm 0.28\end{array}$ & $\begin{array}{r}1.41 \\
1.63 \\
-1.15\end{array}$ & $\begin{array}{r}0.10 \pm 0.24 \\
-0.08 \pm 0.24 \\
0.14 \pm 0.27\end{array}$ & $\begin{array}{r}0.44 \\
-0.33 \\
0.51\end{array}$ \\
\hline
\end{tabular}

and Karasov 1994, Charalambidou et al. 2005), as well as seed retention time in the guts (Murray et al. 1994, Traveset 1998, Traveset et al. 2001c, Santamaría et al. 2002, Charalambidou et al. 2003, 2005, Pollux et al. 2005). The diet of the birds used for our experiments was the same; thus, the differences in seed responses within an individual plant must respond to some intrinsic morphological and/or physiological trait of the bird. For future investigations on the effect of seed ingestion by dispersers on germination, it is of crucial importance to control for this in order to avoid such variability in seed responses.

Although previous studies have reported ultrastructural changes in the coat of seeds after passage through frugivores (Barnea et al. 1990, Mas and Traveset 1999, Traveset et al. 2001c), no quantification of such changes has been made until now. Despite using a number of parameters for this purpose, however, we could not detect any significant difference, either between ingested and non-ingested seeds or among individuals. Interestingly, however, in both plant species we found that changes in seed coat texture after ingestion were much greater in some plants than in others, and that one of the indexes (MM) was indeed correlated with seed germination rate in Phillyrea. This suggests that seed coat texture is a trait that, at least in some species, may be associated with the speed of germination, which usually determines seedling success (Verdú and Traveset 2005). It would thus be worthwhile to investigate further the modifications of this trait within the frugivores' digestive tracts.

Changes in seed coat thickness were not consistent between the two study species either. The coat of Phillyrea seeds became thinner (i.e., abraded) after ingestion, as found also in other species (Marrero and Nogales 2005, Nogales et al. 2005, Tewksbury et al. 2008), but the coat of Myrtus did not change, as also observed in other species (Traveset et al. 2001b). The seed coat is usually formed from the integuments (maternal tissue), although it can also be made up of other tissues such as the nucellus or the endosperm. The number of tissue layers forming the integument is quite variable among species; sometimes only the outer integument (cuticle) makes up the coat, whereas in other cases this consists of several layers (Mayer and Poljakoff-Mayber 1989, Werker 1999). It is thus not surprising that different species will be differently abraded under a specific chemical environment such as that prevailing during the frugivores' gastric and intestinal digestion (Rick and Bowman 1961). For both Phillyrea and Myrtus, but especially the former, we detected much intraspecific variation in seed coat thickness; this trait influenced seed germination rate in these two species, as well as in other species (Nogales et al. 2005, Tewksbury et al. 2008). It is thus essential to consider such intraspecific variation in future germination tests in these types of studies. Moreover, passage through the blackbirds' digestive tract had no consistent effect on seed coat thickness in all individuals from either species. In experiments with captive frugivores (receiving the same diet), we reduce the variation in gut passage time, but in nature such variability is surely much greater, with subsequent consequences for germination patterns. We know from at least one study with Capsicum that seed retention time in the animal's guts is positively associated with the level of coat abrasion, and that ingested seeds with thinner coats are, in turn, less likely to germinate (Tewksbury et al. 2008). Therefore, the prediction by Barnea et al. (1991) that longer retention times cause a stronger reduction of seed coat and, hence, better germination seems to be confirmed, at least for some species. However, as also suggested by Barnea et al. (1991), retention time in the guts is not the only factor involved in reducing coat thickness, as we found in Rubia fruticosa in the Canary Islands (Nogales et al. 2005). For example, the presence of a more or less robust gizzard, as well as the composition of the food ingested, may affect the degree of seed scarification regardless of the time that seeds remain in the digestive tract.

Seed hardness may be positively associated with seed coat thickness, as in Phillyrea, or not, as in Myrtus. Seed passage through blackbirds' digestive tracts influenced this trait differently in the two plant species studied. The hardness of Phillyrea seeds was not influenced by ingestion, despite the fact that the seed coat became thinner, which we partly attribute to the high intra- and interindividual variation in seed hardness (ranging from $<1$ to $25 \mathrm{Nmm}$ ). Variation in this trait also contributes to explaining the variation in germination patterns, because harder seeds took more time to emerge than less resistant ones. In Myrtus, seeds that passed through birds' guts were less deformable than controls and thus broke sooner with the same applied load (i.e., with less work needed). The only other species in which seed resistance to avian digestion has been measured is Sorbus aucuparia (Paulsen et al. 2006); similarly to Myrtus, the work needed to break Sorbus seeds was greater for hand-cleaned seeds than for bird-ingested seeds. 


\section{Consequences for germination and seedling growth}

The ingestion of seeds by blackbirds was found to speed up germination in both species, but especially in Myrtus. Such germination enhancement has been reported in a number of studies testing the effect of frugivores on germination patterns (see reviews in Traveset 1998, Traveset and Verdú 2002, Robertson et al. 2006; Traveset et al. 2007). For Myrtus communis, in particular, Barnea et al. (1991) had already documented that germination was enhanced when seeds were ingested by birds, especially by blackbirds in comparison to bulbuls; they indeed attributed such differences between frugivores to the longer retention time of seeds in blackbirds' guts.

In Phillyrea, at least two of the seed traits measured (permeability and coat thickness) were altered after ingestion and, in turn, were found to directly affect germination rate. Thus, ingested seeds, which were more permeable and had thinner coats, tended to germinate sooner than non-ingested ones. This finding suggests that seed coat thickness in a given species is the result of a compromise between being too thin (with the possibility of becoming too abraded during passage through the frugivore's gut, with a subsequent seed mortality, as has been found in Capsicum annuum; Tewksbury et al. 2008) and too thick (implying a cost for the future seedling, which has to invest energy to emerge from the seed at the expense of a subsequent lower growth rate). Seeds with thicker coats are likely to be more resistant to breakage, and that is probably why hard Phillyrea seeds germinated at a slower rate and produced seedlings that also grew more slowly than those from less resistant seeds. In Myrtus, the two seed traits that were notably modified during passage through blackbirds were seed permeability and seed hardness, although only the former was found in the regression analysis to influence germination patterns (as in Phillyrea, the most permeable seeds germinated sooner and gave larger seedlings). Thincoated Myrtus seeds also germinated at higher rates, regardless of passage through birds' guts. Seed hardness in this species had no effect on germination or seedling growth, suggesting that the micropyle in this case might play a more important role for seedling emergence than resistance of the seed coat to breakage. Water enters mainly through the micropyle in many species and the concentration of water here is very high during the entire imbibition process (Pietrzak et al. 2002). Thin-coated seeds might well be more imbibed in that zone than seeds with thick coats, regardless of their resistance to breakage.

Seed size had no significant effect on germination patterns in either species. The effect of seed size on germination and seedling success has been reported to be positive in a number of species (e.g., Gómez 2004, Alcántara and Rey 2003), but it may also depend upon the environmental conditions (Halpern 2005). In Myrtus, the lack of an effect was unexpected, because large seeds of this species tended to be more permeable than small seeds; the reason for this might be that seed size is not associated with coat thickness and, thus, a large seed may be more permeable than a small one despite having a thicker coat that slows germination rate. Seed coat thickness and permeability were not associated in either Phillyrea or Myrtus. Seeds of both species become more permeable to water (and probably to oxygen, as well) after being ingested by birds, and this is likely to be what mostly accelerates germination, as suggested for other species (Sahai 1995). However, in many species, especially those with thick coats, what may limit germination is not only the capacity of hydration but also the difficulty of seedling emergence.

\section{Conclusions}

In this study we document a number of modifications experienced by the seeds of two fleshy-fruited species after being ingested by frugivorous birds. We found that such modifications were not always consistent in the two species. There is also a high intraspecific variation in seed responses to ingestion, which in turn determines, to a higher or lower degree, the patterns of germination and seedling growth. The capacity of water absorption is increased in ingested seeds in both species and we hypothesize that this is what primarily determines the speed of germination. Moreover, the thickness of the seed coat (which is probably often associated with seed hardness, but not always) also influences the rate at which seedlings emerge and, in some species, even the rate at which they can grow. Therefore, although we still do not know how general this is for other plant species, we might expect that the most permeable seeds of a particular species and those with thinner coats would germinate sooner due to a faster imbibition and to a lower cost of seedling emergence. Some of these seed responses, such as seed hardness, may also differ depending upon the morphological and/or physiological traits of the particular frugivore ingesting the seeds and upon the food that it is consuming in the wild, which affects gut passage time, the level of seed coat abrasion, and, in turn, subsequent germinability. Therefore, there are many factors, both intrinsic and extrinsic to the seed, that contribute to the large variation usually observed in this type of germination test comparing seeds ingested by frugivores with non-ingested seeds. These factors need to be considered in future studies.

The available evidence to date on this subject, especially in the Mediterranean area, confirms that frugivores (especially birds, for which most data exist) contribute to the heterogeneity in germination patterns not only within plant populations but also within plant communities. We now know from a number of studies that plant species within the same community and even within the same functional type may respond very differently to the effect of pulp removal as well as to that of passing through the animals' guts. The present study further shows the variability in responses within a particular species and identifies the mechanisms under- 
lying such variability. In a previous study (Traveset et al. 2001c), we hypothesized that the degree of seed scarification probably varies among plants species, perhaps as a function of factors such as seed coat thickness and texture. Here we confirm with empirical data that such traits are modified in the animals' guts and that such modifications, in turn, can alter germination patterns, although not in an easily predictable way for a given plant species. What we can expect, though, as already pointed out by several authors working in these Mediterranean ecosystems, is that the advantage for plants of such heterogeneity of responses lies in that a larger proportion of their seeds can have successful germination and establishment under the unpredictable rains in these habitats.

\section{ACKNOWLEDGMENTS}

We especially thank Joan Cifre and Fernando Hierro (University of the Balearic Islands) for their help and time measuring seed resistance and taking the pictures at the SEM, respectively. We are also indebted to Julio Martín (U. Vigo) for providing us with the program to measure seed coat ultrastructure, to Javier Tomás (IMEDEA) for help with the image analysis software, and to Asier R. Larrinaga for statistical advice and comments on an early draft. Mariola Polo, Juanjo Pericàs, and Raúl Fernández helped to measure seeds in the laboratory. The comments by two anonymous referees were very valuable to improve the final version of the manuscript. This study is framed within Project CGL2004-04884-C0201/BOS financed by the Spanish Ministry of Education and Science.

\section{Literature Cited}

Alcántara, J. M., and P. J. Rey. 2003. Conflicting selection pressures on seed size: evolutionary ecology of fruit size in a bird-dispersed tree, Olea europaea. Journal of Evolutionary Biology 16:1168-1176.

Aronne, G., and D. Russo. 1997. Carnivorous mammals as seed disperser of Myrtus communis (Myrtaceae) in the Mediterranean shrublands. Plant Biosystems 131:189-195.

Barnea, A., Y. Yomtov, and J. Friedman. 1990. Differential germination of two closely related species of Solanum in response to bird ingestion. Oikos 57:222-228.

Barnea, A., Y. Yom-Tov, and J. Friedman. 1991. Does ingestion by birds affect seed germination? Functional Ecology 5:394-402

Barnea, A., Y. Yomtov, and J. Friedman. 1992. Effect of frugivorous birds on seed dispersal and germination of multiseeded fruits. Acta Oecologica 13:209-219.

Baskin, C. C., and J. M. Baskin. 1998. Seeds. Ecology, biogeography, and evolution of dormancy and germination. Academic Press, San Diego, California, USA.

Charalambidou, I., L. Santamaría, C. Jansen, and B. A. Nolet. 2005. Digestive plasticity in Mallard ducks modulates dispersal probabilities of aquatic plants and crustaceans. Functional Ecology 19:513-519.

Charalambidou, I., L. Santamaría, and O. Langevoord. 2003. Effect of ingestion by five avian dispersers on the retention time, retrieval and germination of Ruppia maritima seeds. Functional Ecology 17:147-753.

Cipollini, M. L., and D. J. Levey. 1997. Secondary metabolites of fleshy vertebrate-dispersed fruits: adaptive hypotheses and implications for seed dispersal. American Naturalist 150:346372

Dinerstein, E., and C. M. Wemmer. 1988. Fruits Rhinoceros eat: dispersal of Trewia nudiflora (Euphorbiaceae) in lowland Nepal. Ecology 69:1768-1774.
Egli, D. B. 1994. Seed growth and development. Pages 127-147 in K. J. Boote, J. M. Bennet, T. Sinclair, and G. M. Paulsen, editors. Physiology and determination of crop yield. Crop Science Society of America, Madison, Wisconsin, USA.

Gómez, J. M. 2004. Bigger is not always better: Conflicting selective pressures on seed size in Quercus ilex. Evolution 58: 71-80.

González, R. C., and R. E. Woods. 2002. Digital image processing, Second edition. Prentice-Hall, Upper Saddle River, New Jersey, USA.

Halpern, S. L. 2005. Sources and consequences of seed size variation in Lupinus perennis (Fabaceae): adaptive and nonadaptive hypotheses. American Journal of Botany 92:205213.

Haralick, R. M., K. S. Shanmugam, and I. Dinstein. 1973. Textural features for image classification. IEEE [Institute of Electrical and Electronics Engineers] Transactions on Systems, Man, and Cybernetics 3:610-621.

Levey, D. J., and A. Grajal. 1991. Evolutionary implications of fruit-processing limitations in cedar waxwings. American Naturalist 138:171-189.

Levey, D. J., and W. H. Karasov. 1994. Gut passage of insects by European starlings and comparison with other species. Auk 111:478-481.

Loiselle, B. A. 1990. Seeds in droppings of tropical fruit-eating birds: importance of considering seed composition. Oecologia 82:494-500

Malo, J. E., and F. Suárez. 1995. Herbivorous mammals as seed dispersers in a Mediterranean dehesa. Oecologia 104:246255.

Marrero, P., and M. Nogales. 2005. A microhistological survey on the trees of a relict subtropical laurel forest from the Macaronesian Islands as a base for assessing vertebrate plant diet. Botanical Journal of the Linnean Society 148:409-426.

Mas, R. E., and A. Traveset. 1999. Efectes de la ingestió per ocells sobre la germinació i la dispersió de dues espècies proximes de Solanum. Bolletí de la Societat d'Història Natural de les Balears 42:69-77.

MathSoft. 1999. S-Plus 2000. Guide to statistics. MathSoft, Seattle, Washington, USA.

Mayer, A. M., and A. Poljakoff-Mayber. 1989. The germination of seeds. Fourth edition. Pergamon Press, Oxford, UK

MediaCybernetics. 2001. Image Pro-Plus Version 4.5.1.2.2. MediaCybernetics, North Reading, Massachusetts, USA.

Meyer, G. A., and M. C. Witmer. 1998. Influence of seed processing by frugivorous birds on germination success of three North American shrubs. American Midland Naturalist 140:129-139.

Murray, K. G., S. Russell, C. M. Picone, K. Winett-Murray, W. Sherwood, and M. L. Kuhlmann. 1994. Fruit laxatives and seed passage rates in frugivores: consequences for plant reproductive success. Ecology 75:989-994.

Nogales, M., C. Nieves, J. C. Illera, D. P. Padilla, and A. Traveset. 2005. Effect of native and alien vertebrate frugivores on seed viability and germination patterns of Rubia fruticosa (Rubiaceae) in the Eastern Canary Islands. Functional Ecology 19:429-436.

Paulsen, T. R., N. R. Gjerdet, and G. Högstedt. 2006. Avian gut passage reduces seed exit costs in Sorbus aucuparia (Rosaceae) as measured by a diametral compression test. Functional Plant Biology 33:401-406.

Paulsen, T. R., and G. Högstedt. 2002. Passage through bird guts increases germination rate and seedling growth in Sorbus aucuparia. Functional Ecology 16:608-616.

Pietrzak, L. N., J. Fregeau-Reid, B. Chatson, and B. Blackwell. 2002. Observations on water distribution in soybean seed during hydration processes using nuclear magnetic resonance imaging. Canadian Journal of Plant Science 82:513-519.

Pollux, B. J. A., L. Santamaría, and N. J. Ouborg. 2005. Differences in endozoochorous dispersal between aquatic plant species, with reference to plant population persistence in rivers. Freshwater Biology 50:232-242. 
Rick, C. M., and R. I. Bowman. 1961. Galápagos tomatoes and tortoises. Evolution 15:407-417.

Robertson, A. W., A. Trass, J. J. Ladley, and D. Kelly. 2006. Assessing the benefits of frugivory for seed germination: the importance of the deinhibition effect. Functional Ecology 20: 58-66.

Rodríguez-Pérez, J., N. Riera, and A. Traveset. 2005. Effect of seed passage through birds and lizards on emergence rate of Mediterranean species: differences between natural and controlled conditions. Functional Ecology 19:699-706.

Sahai, K. 1995. Studies on seed treatments and histochemical characters on water barriers in seed coat of Leucaena glauca (L.) Benth. Journal of Phytological Research 8:97-100.

Samuels, I. A., and D. J. Levey. 2005. Effects of gut passage on seed germination: Do experiments answer the questions they ask? Functional Ecology 19:365-368.

Santamaría, L., I. Charalambidou, J. Figuerola, and A. J. Green. 2002. Effect of passage through duck gut on germination of fennel pondweed seeds. Archiv für Hydrobiologie 156:11-22.

Schupp, E. W. 1993. Quantity, quality and the effectiveness of seed dispersal by animals. Vegetatio 107/108:15-29.

Stanley, M. C., and A. Lill. 2002. Avian fruit consumption and seed dispersal in a temperate Australian woodland. Austral Ecology 27:137.

StatSoft. 2005. STATISTICA for Windows. StatSoft, Tulsa, Oklahoma, USA

Tewksbury, J. J., D. J. Levey, M. Huizinga, D. C. Haak, and A. Traveset. 2008. Costs and benefits of capsaicin-mediated control of gut retention in dispersers of wild chilies. Ecology 89:107-117.

Traveset, A. 1994. Reproductive biology of Phillyrea angustifolia L. (Oleaceae) and effect of galling-insects on its reproductive output. Botanical Journal of the Linnean Society 114:153-166.
Traveset, A. 1998. Effect of seed passage through vertebrate frugivores' guts on germination: a review. Perspectives in Plant Ecology, Evolution and Systematics 1/2:151-190.

Traveset, A., T. Bermejo, and M. F. Willson. 2001a. Effect of manure composition on seedling emergence and growth of two common shrub species of Southeast Alaska. Plant Ecology 155:29-34.

Traveset, A., N. Riera, and R. E. Mas. 2001b. Ecology of fruitcolour polymorphism in Myrtus communis and differentia effects of birds and mammals on seed germination and seedling growth. Journal of Ecology 89:749-760.

Traveset, A., N. Riera, and R. E. Mas. 2001c. Passage through bird guts causes interspecific differences in seed germination characteristics. Functional Ecology 15:669-675.

Traveset, A., A. W. Robertson, and J. Rodríguez-Pérez. 2007. A review on the role of endozoochory on seed germination Pages 78-103 in A. Dennis, R. Green, E. W. Schupp, and D. A. Westcott, editors. Seed dispersal. Theory and its implications in a changing world. CABI Publishing, Wallingford, New York, USA.

Traveset, A., and M. Verdú. 2002. A meta-analysis of the effect of gut treatment on seed germination. Pages 339-350 in D. J. Levey, W. R. Silva, and M. Galetti, editors. Seed dispersal and frugivory: ecology, evolution and conservation. $\mathrm{CAB}$ International, Wallingford, UK.

Verdú, M., and A. Traveset. 2005. Early emergence enhances plant fitness: a phylogenetically controlled meta-analysis. Ecology 86:1385-1394

Wahaj, S. A., D. J. Levey, A. K. Sanders, and M. L. Cipollini. 1998. Control of gut retention time by secondary metabolites in ripe Solanum fruits. Ecology 79:2309-2319.

Werker, E. 1999. Seed anatomy. Gebrüder Borntraeger, Berlin, Germany. 